\title{
Measuring Concern over Coronavirus in an Iranian non-clinical sample using the Coronavirus Disease Concern Scale (COVID-19CS)
}

Mahboubeh Dadfar ( $\sim$ mahboubehdadfar@yahoo.com )

Iran University of Medical Sciences School of Behavioral Sciences and Mental Health https://orcid.org/0000-0003-0620-2570

David Lester

Stockton University

Research article

Keywords: Coronavirus Disease Concern Scale (COVID-19CS), infectious disease, pandemic, Iran, university students

Posted Date: January 8th, 2021

DOI: https://doi.org/10.21203/rs.3.rs-141240/v1

License: (c) (i) This work is licensed under a Creative Commons Attribution 4.0 International License. Read Full License 


\section{Abstract}

\section{Background}

The Coronavirus Disease-2019 (COVID-19) outbreak is a public health problem and a great challenge in the world, including Iran. The aims of the present study were: (a) to investigate the psychometric properties and the factorial structure of the Coronavirus Disease (COVID-19) Concern Scale (COVID19CS), (b) to explore correlations of the COVID-19CS scores with the Fear of COVID-19 Scale (FCV-19S), and (c) to examine gender differences.

\section{Methods}

This was a descriptive cross-sectional study. A convenience sample of 125 medical students was recruited. The COVID-19CS and FCV-19S were administered to the students. The data were analyzed with descriptive statistics, $t$-tests, Pearson correlation coefficients, and a Principal Components factor analysis.

\section{Results}

Cronbach's $a$ was .94. Three factors were extracted labeled "Infection/Unsafety", "Instability/Fear of Social Isolation", and "Insecurity/Death Fear." The COVID-19CS score was positively correlated with the FCV-19S score. There was no sex difference in the COVID-19CS score.

\section{Conclusions}

The COVID-19CS is a multidimensional scale. Just over half (56.3\%) of students reported concern of COVID-19 and, therefore, appropriate policy-making and evidence-based psycho educational training are necessary to reduce their concern over COVID-19.

\section{Background}

For more than several months the world suffers from the SARS-CoV-2 (Severe Acute Respiratory Syndrome Coronavirus 2) virus, named Coronavirus Disease-2019 (COVID-19) pandemic. It is a public health problem [1], and a great challenge to the world, including Iran [2, 3].

Iran is one of the more severely affected countries of the world health organization (WHO) with a total of $1,040,547$ known cases and 50,310 deaths (596/million population) as of 7 December, 2020 [4].

Psychological distress and mental health issues resulting from the COVID-19 such as anxiety, worry, fear, phobia, stress, substance use, and suicide, can be assessed $[5,6,7,8,9,10,11,12]$.

The aims of the present study were: (a) to investigate psychometric properties and to explore the factorial structure of the Coronavirus Disease Concern Scale (COVID-19CS), (b) to explore correlation of the COVID19CS scores with the Fear of COVID-19 Scale (FCV-19S), and (c) to examine gender differences. 


\section{Methods}

\section{Study design and participants}

This was a descriptive cross-sectional study. A convenience sample of Iranian medical students was recruited in July 2020. The sample size was calculated using Cochran's formula [13].

\section{Measure}

The Coronavirus Disease Concern Scale (COVID-19CS), adapted from the SARS Fear Scale (SFS [14], is a self-report scale and is used for assessing concern about the coronavirus. It has 18 items. The participants indicate their level of agreement with the statements using a 4-point Likert scale ranging from 0 to 3: definitely false (0), somewhat false (1), somewhat true (2), and definitely true (3). Total scores range from 0 to 54 , with a higher score indicating a higher concern over COVID-19.

In the present study, first the SARS Fear Scale (SFS) developed by Ho et al. [14] was translated into Farsi by a native Farsi speaker, back-translated, and compared to the original English version. Ho et al. had suggested that the SFS should be adapted for other infectious diseases [14]. Therefore, we adapted it for COVID-19, and then used in the present study. This scale is a translation of the Ho et al. scale [14], where SARS is simply replaced by COVID-19, and is an adapted from of the SFS, named COVID-19CS (see Appendixes A \& B).

The Fear of COVID-19 Scale (FCV-19S), originally developed in Persian (Farsi) [15], is a self-report scale consisting of 7 items used for assessing fear of coronavirus. The participants indicate their level of agreement with the statements using a 4-point Likert scale ranging from strongly disagree (1) to strongly agree (5). The total score ranged from 7 to 35 , with a higher score indicating more fear of COVID-19 [15].

The FCV-19S has Arabic, Bangla, Chinese, English, Ethiopian Amharic, French, Greek, Hebrew, Indian, Italian, Japanese, Malay, Russian, Spanish, Tamil, and Urdu versions. Cronbach's alpha for the FCV-19S were between .80 to $.89[7,12,16,17,18,19,20,21,22,23,24,25,26,27,28,29,30,31,32,33,34,35,36]$.

\section{Data collection}

The COVID-19CS and FCV-19S were administered to 130 medical students who were resident in three student dormitories at the Iran University of Medical sciences. We have used this specific group of student as our sample, for reason that only medical students were present at the dormitories and due to the prevalence COVID-19, the university had not been permitted to other students for presence at that time. Also, it is well documented that medical students, in particular, have higher levels of mental health issues. The students were invited to participate voluntarily in the study, and the study's objective was explained to them. Verbal informed consent was obtained from all participants. The reason was being in critical situation of COVID-19 and the Institutional Review Board approved this procedure. Confidentiality was assured, and the students' anonymity was maintained. A total of 125 students ( $96 \%$ response rate) returned the scale. The scales were distributed by directors of student dormitories. Data were collected in 
two weeks. This study was performed in line with the principles of the Declaration of Helsinki. Ethical approval was obtained from the Institutional Review Board (without committee's reference number) at Iran University of Medical sciences, Iran, for the study.

\section{Data analyzes}

For determination of the normality of the data and equality of variances, the Kolmogorov-Smirnov test and Levene's test were used, respectively. The data were analyzed with descriptive statistics (mean, standard deviations), $t$ tests, Pearson correlation coefficients, and a Principal Components factor analysis to identify the number of factors to be retained. The criterion of eigenvalues greater than or equal to 1.0 was followed and the Varimax orthogonal rotation of axes was adopted. The SPSS/WIN version 26 was used.

\section{Results}

The mean age of the students was $24.04(S D=1.99) ; 50.4 \%$ male; and the majority of participants $(82.4 \%)$ were studying in a general physician (GP) program. The mean total score for the COVID-19CS was $30.41(\mathrm{SD}=12.86)$.

Mean scores on the COVID-19CS items ranged from 0.89 (SD =1.14) (for dream about myself-familiescolleagues getting infected), to 2.28 ( $S D=.74)$, (for fear that I will infect others). Cronbach's $a$ was .94 . The item-total correlations ranged from .61 to .84 (significant at the .01 level).

The Kaiser-Meyer-Olkin Measure of Sampling Adequacy for the COVID-19CS was 0.898. The Bartlett's Test of Sphericity Chi-Square was 1537.431 ( $\mathrm{df}=153, p>.000$ ). Three factors were extracted for the COVID-19CS (Factor loadings $>.5,66.05 \%$ of total variance). Factor 1 (items 1, 2, 4, 5, 10, and 18) was labeled "Infection/Unsafety." Factor 2 (items 12, 13, 14, 15, 16, and 17) was labeled "Instability/Fear of Social Isolation." Factor 3 (items 4, 6, 7, 8, and 11) was labeled "Insecurity/Death Fear." Items 3 and 9 were not significantly loaded on any of the three factors (see Table 1 and Fig. 1). 
Factor loadings $>.5$ of the Coronavirus Disease (COVID-19) Concern Scale (COVID-19CS)

\section{Item COVID-19CS}

Coronavirus Disease (COVID-19) makes me...

1. Fear that I will be infected.

2. Fear that I will infect others.

3. Suspect whether I have been infected or not.

4. Feel that the virus is very close to me, (and the virus may) invade my body anytime.

5. Feel very unsafe about myself.

6 . Feel that life is threatening.

7. Feel that I have lost control of life.

8. Think about death-dying.

9. Feel that the virus will get out of control-spread continuously.

10 . Worry if my family will be infected.

11. Dream about myself-families-colleagues getting infected.

12. Fear being quarantine or forced to limit activities.

13. Feel distressed because of the upsurge in workload.

14. Feel being discriminated of by others.

15 . Worry if my family or friends will keep a distance from me due to my job duties.

16. Worry if I will be assigned to Coronavirus disease wards.

17. Worry about other health problems regarding myself.

.60

18. Worry about other health problems regarding my family members.

Eigen value

9.101 .591 .20

$\%$ of variance

$50.6 \% 8.83 \%$

$.67 \%$

Factor 1 (items 1, 2, 4, 5, 10, and 18) labelled: Infection/Unsafety

Factor 2 (items 12, 13,14,15, 16, and 17) labelled: Instability/ Fear of Social Isolation

Factor 1 (items 5, 6, 7, 8, and 11) labelled: Insecurity/Death Fear

Items 3 and 9 were not significantly loaded (loading $>.5$ ) on any of the three factors. 
The Cronbach's a was .88 for factors 1 and 2, and .90 for factor 3 . The COVID-19CS total score was positively correlated $(r=.86, .89$, and .90$)$ with its three factors, respectively. Factor 1 positively correlated $(r=.63$, and .76) with factors 2 and 3 , respectively. Factor 2 positively correlated $(r=.72)$ with factor 3 (significant at the .01 level).

The COVID-19CS score was positively correlated with the FCV-19S score $(r=.67)$. Scores for factors 1,2 , and 3 of the COVID-19CS were positive correlated with the FCV-19S total score $(r=.58, .54$, and .63, respectively), indicating good validity.

The gender difference for the COVID-19CS score was not significant (mean for men 31.60, $S D=14.89$; and mean for women 29.16, $S D=10.48, \mathrm{t}=-1.05, \mathrm{p}>.05$ ).

\section{Discussion}

On the COVID-19CS, Iranian students $(56.31 \%)$ reported moderate concern about COVID-19. The internal consistency of the COVID-19CS was high, consistent with the study of Ho et al. (2005) using the SFS in a sample of hospital staff.

The COVID-19CS appeared to be a three-factorial scale, consistent with the study of Ho, et al. (2005) with the SFS, who also obtained three factors (67.21\% of the total variance), labelled; "Infection", "Insecurity", and "Instability." In the present study items 3 and 9 were not significant loaded on any of the three factors. So, these items of the COVID-19CS should be discarded from the scale.

The COVID-19CS score was positively and moderately correlated with the FCV-19S score $(r=.67)$. On the SFS, Ho et al. reported a positive correlation with the Chinese Impact of Events Scale-Revised (CIES-R), which measures posttraumatic stress symptoms, and negative correlation with the Chinese Self-Efficacy Scale [14].

Inconsistent with several other studies on the fear of coronavirus $[7,19,23,30,33,34,36,37,38$, 39], we found no sex difference on the concern over coronavirus. These contradictory findings may be partly due to the use of samples with different cultural back-grounds, differences in age ranges and participant characteristics, a different used scale, and sample sizes. However, consistent with the present study, Perz et al. [28] reported no sex differences on the fear of coronavirus in an American college samples. Also, and Caycho-Rodríguez et al. [40] found a similar finding in an Argentines' sample.

The present study has some limitations. First, this is a cross-sectional design. Second, it is uncertain to what extent the results can generalize to populations other than medical students and/or Iranians. Third, the use of medical students introduces range restriction, not only by educational level and vocational preference but also because of their presumed good knowledge about the nature of the disease. Fourth, the sample size was low and quite limited and that somewhat hampers the interpretation of some findings, such as the sex differences. Nevertheless, as the number of infected patients has not yet been 
stopped, it is hoped that the study will be made public soon and will be used for the expansion of many studies and policies.

\section{Conclusion}

The COVID-19CS is a multidimensional scale with good psychometric properties in the present sample from Iran. This study provides evidence for the usefulness of the COVID-19CS for assessing concern of COVID-19 in Iranian students and in non-clinical settings. Sixteen items of the COVID-19CS can be used to assess three concerns over COVID-19 (Infection/Unsafety; Instability/Fear of Social Isolation; and Insecurity/Death Fear). The students reported concern of COVID-19 and, therefore, appropriate policymaking and evidenced-based psycho educational training are necessary to reduce their concern over COVID-19.

\section{Declarations}

\section{- Ethical approval and consent to participate}

This study was performed in line with the principles of the Declaration of Helsinki. Ethical approval was obtained from the Institutional Review Board (without committee's reference number) at Iran University of Medical sciences, Iran, for the study. All participants provided verbal informed consent. The reason was being in critical situation of COVID-19 pandemic and the Institutional Review Board approved this procedure.

\section{- Consent for publication}

Not Applicable

\section{- Availability of supporting data}

The datasets generated during and/or analysed during the current study are available from the corresponding author on reasonable request.

\section{- Competing interests}

The authors declare that they have no conflict of interest regarding the publication of this paper.

\section{- Funding}

No funding was received.

\section{- Authors' contribution}

MD (Conceptualization; Data curation; Formal analysis; Methodology; Project administration; Validation; Writing - original draft; Writing - review \& editing) DL (Formal analysis; Validation; Writing - review \& 
editing). All authors have read and approved the manuscript.

\section{- Acknowledgements}

We thank all the students for their participation in the study, and the research assistants for helping in the collection of data.

\section{References}

1. World Health Organization. Coronavirus disease (COVID-2019): Situation report-95. 2020; https://www.who.int/docs/default-source/coronaviruse/situation-reports/20200424-sitrep-95-covid19. pdf?sfvrsn = e8065831_4.

2. Afshar Jahanshahi A, Mokhtari Dinani M, Nazarian Madavani A. et al. The distress of Iranian adults during the Covid-19 pandemic - more distressed than the Chinese and with different predictors. Brain Behav Immun. 2020;87:124-5.

3. Nourizadeh M, Rasaee MJ, Moin M. COVID-19 pandemic: A big challenge in Iran and the world. Iran J Allergy Asthma Immunol. 2020;19(Supple.1):1-2. doi:10.18502/ijaai.v19i(s1.r1).2846.

4. Worldometers. COVID-19 coronavirus pandemic. 2020; https://www.worldometers.info/coronavirus/.

5. Arpacia I, Karataşb K, Baloğluc M. The development and initial tests for the psychometric properties of the COVID-19 Phobia Scale (C19P-S). Pers Individ Differ. 2020;164:110108. https://doi.org/10.1016/j.paid.2020.110.

6. Galea S, Merchant RM, Lurie N. The mental health consequences of COVID-19 and physical distancing: The need for prevention and early intervention. JAMA Intern. Med. 2020; Retrieved from. 10.1001/jamainternmed.2020.1562.

7. Gritsenko V, Skugarevsky O, Konstantinov V, et al. COVID 19 fear, stress, anxiety, and substance use among Russian and Belarusian university students. Int J Ment Health Addiction. 2020. https://doi.org/10.1007/s11469-020-00330-z.

8. Kanga L, Maa S, Chenb M, et al. Impact on mental health and perceptions of psychological care among medical and nursing staff in Wuhan during the 2019 novel coronavirus disease outbreak: A cross-sectional study. Brain Behav Immun. 2020;87:11-7.

9. Mamun MA, Griffiths MD. First COVID-19 suicide case in Bangladesh due to fear of COVID-19and xenophobia: Possible suicide prevention strategies. Asian J Psychiatry. 2020;51:102073. https://doi.org/10.1016/j.ajp.2020.102073.

10. Moghanibashi-Mansourieh A. Assessing the anxiety level of Iranian general population during COVID-19 outbreak. Asian J Psychiatry. 2020. https://doi.org/10.1016/j.ajp.2020.102076.

11. Ornell F, Schuch JB, Sordi AO, et al. Pandemic fear" and COVID-19: Mental health burden and strategies. Brazilian J Psychiatry. 2020. doi:10.1590/1516-4446-2020-0008.

12. Ransing R, Ramalho R, Orsolini L, et al. Can COVID-19 related mental health issues be measured? Brain Behav. Immun. 2020. http:doi.org/doi:10.1016/j.bbi.2020.05.049. 
13. Cochran WG. Sampling techniques. 2nd ed. New York: John Wiley and Sons, Inc; 1963.

14. Ho SMY. Kwong-Lo RSY, Mak CWY, et al Fear of Severe Acute Respiratory Syndrome (SARS) among health care workers. J Consult Clin Psychol. 2005; 73(2): 344-9.

15. Ahorsu DK, Lin C-Y, Imani V. et al. The Fear of COVID-19 Scale: Development and initial validation. Int J Ment Health Addiction. 2020; 1-9. https://doi.org/10.1007/s11469-020-00270-8.

16. Akihiro Masuyama A, Shinkawa H, Kubo T. Validation and psychometric properties of the Japanese version of the Fear of COVID-19 Scale among adolescents. Int J Ment Health Addiction. 2020. https://doi.org/10.1007/s11469-020-00368-z.

17. Alyami $M$, Henning $M$, Krägeloh $C U$, et al. Psychometric evaluation of the Arabic version of the Fear of COVID-19 Scale. Int J Ment Health Addiction. 2020. https://doi.org/10.1007/s11469-020-00316-X.

18. Bharatharaj J, Alyami M, Henning MA, et al. Tamil version of the Fear of COVID-19 Scale. Res Square. 2020; 1-13. https://doi.org/10.21203/rs.3.rs-40914/v1.

19. Broche-Pérez Y, Fernández-Fleites Z, Jiménez-Puig E, et al. Gender and fear of COVID-19 in a Cuban population sample. Int J Ment Health Addiction. 2020. https://doi.org/10.1007/s11469-020-00343-8. Advance online publication.

20. Chang K-C, Hou WL, Pakpour AH, et al. Psychometric testing of three COVID-19-related scales among people with mental illness. Int J Ment Health Addiction. 2020. https://doi.org/10.1007/s11469-02000361-6.

21. Elemo AS, Satici SA, Griffiths MD. The Fear of COVID-19 Scale: Psychometric properties of the Ethiopian Amharic version. Int J Ment Health Addiction. 2020. https://doi.org/10.1007/s11469-02000448-0.

22. Harper CA, Satchell L, Fido D, et al. Functional fear predicts public health compliance in the COVID-19 pandemic. PsyArXiv. 2020. 10.31234/OSF.IO/JKFU3.

23. Huarcaya-Victoria J, Villarreal-Zegarra D, Podestà A, et al. Psychometric properties of a Spanish version of the Fear of COVID-19 Scale in general population in Lima, Peru. Int J Ment Health Addiction. 2020. https://doi.org/10.1007/s11469-020-00354-5.

24. Khalid Mahmood Q, Rizvi Jafree S, Qureshi WA. The psychometric validation of FCV19S in Urdu and socio-demographic association with fear in the people of the Khyber Pakhtunkhwa (KPK) Province in Pakistan. Int J Ment Health Addiction. 2020. https://doi.org/10.1007/s11469-020-00371-4.

25. Mailliez M, Griffiths MD, Carre A. Validation of the French version of the Fear of COVID-19 Scale and its associations with depression, anxiety and differential emotions. Res Square. 2020; Advanced Online Publication. https://doi.org/10.21203/rs.3.rs-46616/v1.

26. Pakpour AH, Griffiths MD, Chang K-C, et al Assessing the fear of COVID-19 among different populations: A response to Ransing et al. (2020). Brain Behav. Immun. 2020; 89: 524-525.

27. Pang NTP, Kamu A, Hambali NLB, et al. Malay version of the Fear of COVID-19 Scale: Validity and reliability. Int J Ment Health Addiction. 2020. https://doi.org/10.1007/s11469-020-00355-4. 
28. Perz CA, Lang BA, Harrington R. Validation of the Fear of COVID-19 Scale in a US college sample. Int J Ment Health Addiction. 2020; 1-11. https://doi.org/10.1007/s11469-020-00356-3.

29. Reznik A, Gritsenko V, Konstantinov V, et al. COVID-19 fear in Eastern Europe: Validation of the Fear of COVID-19 Scale. Int J Ment Health Addiction. 2020. https://doi.org/10.1007/s11469-020-00283-3.

30. Sakib N, Mamun MA, Bhuiyan Al, et al. Psychometric validation of the Bangla fear of COVID-19 scale: Confirmatory factor analysis and Rasch analysis. Int J Ment Health Addiction. 2020; 1-22. https://doi.org/10.1007/s11469-020-00289-x.

31. Satici B, Gocet-Tekin E, Deniz ME, et al. Adaptation of the Fear of COVID-19 Scale: Its association with psychological distress and life satisfaction in Turkey. Int J Ment Health Addiction. 2020. https://doi.org/10.1007/s11.

32. Soraci P, Ferrari A, Abbiati FA, et al. Validation and psychometric evaluation of the Italian version of the Fear of COVID-19 Scale. Int J Ment Health Addiction. 2020. https://doi.org/10.1007/s11469-02000277-1.

33. Tsipropoulou V, Nikopoulou V, Holeva V, et al. Psychometric properties of the Greek version of FCV19S. Int J Ment Health Addiction. 2020;1:1-10. https://doi.org/10.1007/s11469-020-00319-8.

34. Tzur Bitan D, Grossman-Giron A, Bloch Y, et al. Fear of COVID-19 scale: Psychometric characteristics, reliability and validity in the Israeli population. Psychiatry Res. 2020. https://doi.org/10.1016/j.psychres.2020.113100.

35. Winter T, Riordan BC, Pakpour AH, et al. Evaluation of the English version of the Fear of COVID-19 Scale and its relationship with behavior change and political beliefs. Int J Ment Health Addiction. 2020. https://doi.org/10.1007/s11469-020-00342-9. Advance online publication.

36. Dadfar M, Mohagegh F, Sanadgol S, et al. The Fear of COVID-19 Scale (FCV-19S): A study of Iranian students. Mank. Q. in press.

37. Doshi D, Karunakar P, Sukhabogi JR, et al. Assessing coronavirus fear in Indian population using the Fear of COVID-19 Scale. Int J Ment Health Addiction. 2020; 1-9. https://doi.org/10.1007/s11469020-00332-x.

38. Limcaoco RSG, Mateos EM, Fernandez JM, et al. Anxiety, worry and perceived stress in the world due to the COVID-19 pandemic, March 2020. Preliminary Results, medRxiv. 2020; https://doi.org/10.1101/2020.04.03.20043992.

39. Qiu J, Shen B, Zhao M, et al. A nationwide survey of psychological distress among Chinese people in the COVID-19 epidemic: Implications and policy recommendations. Gen Psychiatry. 2020. https://doi.org/10.1136/gpsych-2020-100213. 33, Article e100213.

40. Caycho-Rodríguez T, Vilca LW, Cervigni M, Gallegos M, Martino P, Portillo N, Barés I, Calandra M, Videla CB. (2020) Fear of COVID-19 scale: Validity, reliability and factorial invariance in Argentina's general population. Death Stud. 2020; https://doi.org/10.1080/07481187.2020.1836071.

\section{Figures}




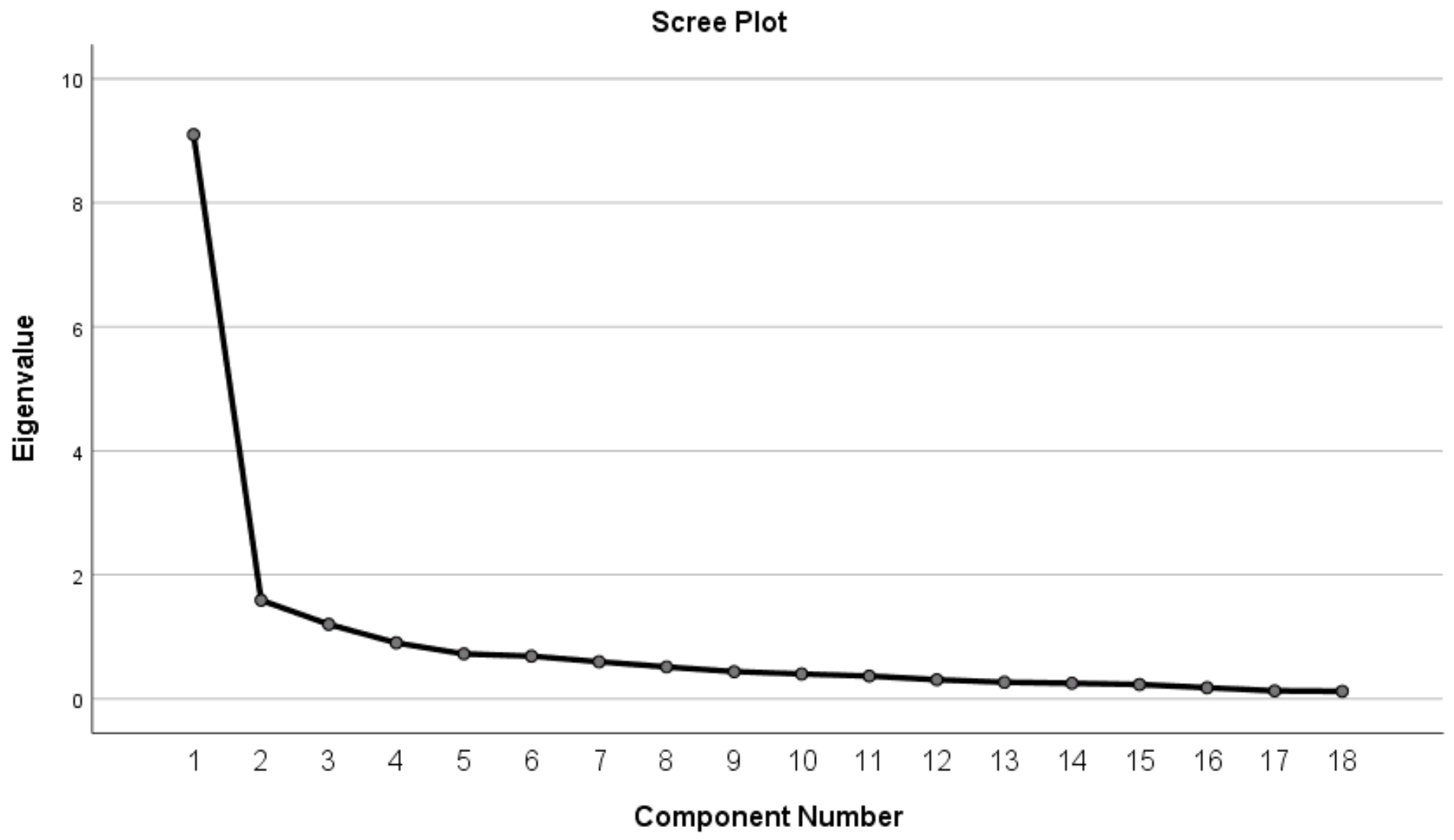

Figure 1

Scree plot of the COVID-19CS

\section{Supplementary Files}

This is a list of supplementary files associated with this preprint. Click to download.

- Appendix.docx 